\title{
Comparing crowdworkers' and conventional knowledge workers' self-regulated learning strategies in the workplace
}

\author{
ANOUSH MARGARYAN, University of West London, United Kingdom
}

\begin{abstract}
This paper compares the strategies used by crowdworkers and conventional knowledge workers to self-regulate their learning in the workplace. Crowdworkers are a self-employed, radically distributed workforce operating outside conventional organisational settings; they have no access to the sorts of training, professional development and incidental learning opportunities that workers in conventional workplaces typically do. The paper explores what differences there are between crowdworkers and conventional knowledge workers in terms of self-regulated learning (SRL) strategies they undertake. Data were drawn from four datasets using the same survey instrument. Respondents included crowdworkers from FigureEight (previously CrowdFlower) and Upwork platforms and conventional knowledge workers in the finance, education and healthcare sectors. The results show that the majority of crowdworkers and conventional knowledge workers used a wide range of SRL strategies. Among 20 strategies explored, a statistically significant difference was uncovered in the use of only one strategy. Specifically, crowdworkers were significantly less likely than the conventional workers to articulate plans of how to achieve their learning goals. The results suggest that, despite working outside organisational structures, crowdworkers are similar to conventional workers in terms of how they self-regulate their workplace learning. The paper concludes by discussing the implications of these findings and proposing directions for future research.
\end{abstract}

\section{BACKGROUND}

In recent years, new forms of digitally-mediated knowledge work practices have emerged (Eurofound, 2015; Huws, 2014; Lehdonvirta and Ernkvist, 2011). One such form of digital work is crowdwork - a type of labour whereby a large number of people from across the world are brought together within Internet-based platforms to carry out tasks for pay (Kuek et al, 2015; Schmidt, 2017). Digital work is an emergent domain and the terminology is in flux. For the purpose of this paper, we define 'crowdwork' as crowdsourced, paid labour in which both the coordination 
and delivery of work occurs entirely online, within digital platforms or apps. The types of digital, crowdsourced labour that are coordinated online, but where the actually delivery of services occurs offline (for example, taxi hailing platforms such as Uber, food delivery services like Deliveroo, or domestic help apps like TaskRabbit) and those types of digital labour that are not paid (such as online volunteering or citizen science initiatives) are not included in the definition of 'crowdwork' and are therefore beyond the scope of this paper.

In crowdwork, the platforms act as intermediaries between people or organisations - individual entrepreneurs, start-up companies, or large enterprises - who post tasks and crowdworkers who perform them (Corporaal and Lehdonvirta, 2017; Kuek et al, 2015). The platforms help oversee the definition, submission, acceptance and payment for the work done (Degryse, 2016). Examples of crowdwork platforms are Amazon Mechanical Turk (MTurk), Upwork, People Per Hour, Freelancer and FigureEight (previously CrowdFlower). Crowdwork tasks range from microwork tasks to macro-size projects and assignments (Kuek et al., 2015). Microwork is a form of crowdwork in which large projects outsourced to crowdwork platforms by clients are broken down into small units of work (called micro-tasks) and posted on the platform for crowdworkers to carry out for pay. Microtasks can be completed in seconds or minutes and are generally considered not to require specialised skills beyond basic computer and Internet literacy. Examples of microtasks are tagging images, rating public sentiment about a product on social media, finding or verifying information on the Web, writing short content, for example short product descriptions, or carrying out basic administrative tasks such as data entry or transcription (Gadiraju, Kawase, and Dietze, 2014). In contrast, the macro-task platforms, which are sometimes called 'online freelancing' platforms, specialise in larger and more complex projects, requiring professional skills and performed over longer periods of time - hours, days or months. Examples of macro-tasks are software or graphic design; video production; ghost-writing; data analytics; business plan development; and accounting or legal advice (Schmidt, 2017).

Crowdwork is a growing form of work both in the developing and developed countries. For example, $5-9 \%$ of the EU population and $5 \%$ of the US population have been estimated to be involved in crowdwork ${ }^{1}$ (Huws, Spencer and Joyce, 2016; Pew Research Centre, 2016). A recent analysis identified 26\% annual growth in the crowdwork industry (Lehdonvirta, 2017). Crowdwork platforms are forecast to expand, raising the global annual GDP by up to $\$ 2.7$ trillion, with an estimated 540 million people worldwide potentially engaging in crowdwork over the next decade (Manyika et al, 2015).

Crowdwork has been criticised for being mundane, routine, bringing about deskilling and discouraging workers from using and developing their own skills and know-how (Degryse, 2016; Irani, 2015; Schmidt, 2017). Yet there has been paucity of empirical research on crowdworkers' use and development of their skills, their learning practices, and their own views about their

${ }^{1}$ The figures refer to workers who reported engaging in crowdwork at the time of the survey (January-April 2016 for the EU sample; and July-August 2016 for the US sample). 
learning experiences and expectations within these platforms. Emergent research findings suggests that crowdworkers do develop different skills through their work on the platforms, ranging from learning online interaction etiquette, new languages to interact with clients, business development, marketing, negotiating, networking, customer relations and communication, digital literacy and technical skills such as software development, problem-solving, math or writing skills (Barnes, Green and de Hoyos, 2015; Green, de Hoyos, Barnes, Baldau and Behle, 2014; Gupta, 2017). Also, empirical research shows that crowdwork requires a set of complex and non-trivial skills, for example learning how to use and navigate the often opaque and non-intuitive interfaces of the platforms or how to find stimulating and well-paid tasks (Gupta, 2017; Martin, O'Neill, Gupta and Hanrahan, 2016; Silberman, Irani and Ross, 2010). Most importantly, a recent scoping study of crowdworkers' learning practices uncovered evidence of a considerable number and range of workplace learning activities and self-regulatory learning strategies being undertaken by crowdworkers to support their work on the platforms (Margaryan, 2016; Margaryan, forthcoming).

Crowdwork challenges the traditional patterns of individual agency, organisation and responsibility for learning and development in the workplace (Littlejohn and Margaryan, 2014; Nickerson, 2014). Crowdwork platforms do not provide the sorts of training, workplace learning and professional development opportunities that are typically available within conventional workplaces. Also, crowdworkers lack structural opportunities to access incidental learning and knowledge sharing opportunities that are available within conventional organisational settings. This is because crowdworkers (especially microworkers) tend to be anonymous to each other and their clients on these platforms and because the platform tasks are designed to be largely autonomous and not to require interdependences or collaboration with others to complete.

In practice, this means that crowdworkers have to initiate and direct their own learning, without recourse to the organisational, legal, structural, technological, financial and motivational scaffolds typically available within the conventional workplaces. In this radically distributed and fragmented form of work, how do crowdworkers go about organising and managing their learning and development and how do their learning practices compare to those of knowledge workers in conventional workplaces? Within the field of workplace learning, the learning practices of conventional knowledge workers have been studied extensively, demonstrating that deep and powerful learning occurs through everyday work (e.g. Billett, 2010; Billett, Harteis and Etelapelto, 2008; Boshuizen, Bromme and Gruber, 2004; Dochy, Gijbels, Segers and van den Bossche, 2011; Eraut, 1994; Felstead, Fuller, Jewson and Unwin, 2009; Illeris, 2011; Littlejohn and Margaryan, 2014; Malloch, Cairns, Evans and O-Connor, 2011). However, the workplace learning practices of crowdworkers are presently not well-understood and the similarities and differences with learning practices of knowledge workers in conventional workplace settings have not been researched.

This paper aims to contribute empirical evidence to address this gap in the literature. In particular, the paper analyses similarities and differences in the use of self-regulated learning (SRL) strategies by crowdworkers on two large crowdwork platforms, Upwork and FigureEight, and conventional 
knowledge workers in the financial services, education and healthcare sectors. The analysis draws on the findings of questionnaire surveys within these different samples, using the same instrument, the Self-Regulated Learning at Work Questionnaire (Fontana, Milligan, Littlejohn and Margaryan, 2015). The study is guided by the following research question:

RQ. What, if any, differences are there in crowdworkers' and conventional knowledge workers' use of self-regulated learning strategies in the workplace?

In the next section, we summarise key previous research on self-regulated learning in the workplace, both in crowdwork platforms and in conventional workplaces. We then present and discuss the findings of our comparative analysis. We conclude by proposing topics for future research.

\section{PREVIOUS RESEARCH}

Self-regulated learning (SRL) is defined as '. . . self-generated thoughts, feelings and actions that are planned and cyclically adapted to the attainment of personal goals' (Zimmerman, 2005, p. 14). Self-regulated learning encompasses three dimensions: affective (feelings, emotions), metacognitive (knowledge states, reasoning, cognitive strategies) and behavioural (actions, behavioural strategies) (Boekaerts, Pintrich and Zeidner, 2005). The focus of the analysis in this paper is on behavioural self-regulation: the actions and behavioural strategies crowdworkers and conventional knowledge workers undertake to self-regulate their learning and professional development in their workplaces. Examples of behavioural SRL strategies are searching for information, note taking, help-seeking, eliciting feedback, observing and replicating other people's strategies, planning learning goals and strategies, self-reflection and self-evaluation.

There are over 16 different self-regulatory theories focusing either on the structure, phases, or content of self-regulation (Sitzmann and Ely, 2011). Zimmerman's three-phase SRL model (Zimmerman, 2005) has been especially influential in the domain of learning and education. Zimmerman's model postulates that individuals self-regulate their learning through three cyclical phases of strategic planning, implementation and self-evaluation. Each of these phases incorporate a range of self-regulatory behavioural strategies, for example identifying long-term and short-term learning goals, setting personal performance standards, monitoring and modifying goals and learning strategies, self-efficacy and intrinsic value of work tasks, reaching out to others for feedback and self-reflection (Zimmerman, 2005).

Although there is an extensive body of literature on SRL, most research has focused on learning in formal, educational settings rather than informal, on-the-job, workplace learning contexts (Boekaerts et al, 2005; Siztmann and Ely, 2011). Therefore, much of what is currently known about how people self-regulate their learning is based on studies of pupils and students in schools and universities rather than professionals in the workplace. Organisational psychologists have studied 
self-regulation in workplaces, however this literature has largely focused on the self-regulation of work performance and work behaviour more broadly, rather than the learning behaviours specifically (Kanfer, Chen and Pritchard, 2008; Locke and Latham, 2013; Lord, Diefendorff, Schmidt and Hall, 2010). In the field of teacher training, a small body of literature examined selfregulated learning strategies among school teachers and university lecturers (Bolhuis and Voeten, 2004; van Eekelen, Boshuizen and Vermunt, 2005; Tillema \& Kremer-Hayon, 2002). These studies, however, are too specific to the teaching profession and to work in formal educational settings, therefore the extent to which the findings produced in these studies can help explain SRL strategies in non-educational knowledge work settings is unclear. Sitzmann \& Ely (2011) called for researchers studying self-regulation to 'adjust their focus to accommodate how learning occurs in the modern workplace' (p. 438).

In response to this call, several recent studies focused on identifying and describing self-regulated learning strategies of professionals who were knowledge workers employed in a range of organisational domains in the finance, energy, education and healthcare settings. First, Margaryan, Littlejohn and Milligan (2013) examined the self-regulated learning strategies that knowledge workers in an energy company (engineers, chemists, R\&D researchers, internal consultants and HR and procurement specialists) undertook to plan and attain their learning goals. The analysis of workers' narrative accounts of their SRL practices identified that SRL in the workplace is structured by and deeply integrated with work tasks and priorities and that learning goals are driven by the requirements of the work tasks in the short-term and by the workers' individual career progression aspirations in the long-term. Margaryan et al (2013) also found that the workplacebased SRL strategies had a prominent social dimension: in the course of planning and attainment of their learning goals, knowledge workers often drew upon others within their personal and professional networks in order to diagnose their learning needs, seek feedback and source relevant knowledge. Previous research in organisational psychology demonstrated that, in the workplace, people exert mutual influence on each other's goal setting through social pressure, conveyance of normative information, acting as role models or generating competition (Earley \& Kanfer, 1985). Finally, Margaryan et al (2013) uncovered lack of uptake of self-reflection strategies among these knowledge workers; this finding is in line with studies in teacher training which also identified lack of planned and structured reflection among teachers (van Eekelen et al, 2005).

Another study examined self-regulated learning strategies among knowledge workers in financial services organisations, in particular analysing the role of the SRL strategies in predicting workplace learning more broadly (Milligan, Fontana, Littlejohn and Margaryan, 2015). The study found that the context of workplace learning (tasks, organisational factors) affected what was learned and what SRL strategies people undertook in the workplace, and that in turn the SRL strategies mediated the relationship between the workplace learning activities and the context. In a series of follow-up interviews with these financial services workers, Littlejohn, Milligan, Fontana and Margaryan (2016) uncovered that those workers who frequently undertook a wide range of SRL strategies perceived learning as having a long-term value for their work and career, whereas those who reported low levels of use of SRL strategies tended to focus on the short-term benefits, for example 
paybacks in terms of their immediate work tasks. Littlejohn et al (2016) further identified that the choice of SRL strategies was influenced by the nature of the work task and the resources available to these workers, emphasising the importance of organisational context in workers' ability and willingness to exercise self-regulation.

A third study examined how healthcare professionals self-regulate their learning in the context of a massive open online course (MOOC) on clinical trials (Milligan and Littlejohn, 2016). The context of this study is somewhat different from the previously discussed studies of the finance and energy sector workers, in that here the workers were participating in a structured course, although the course was closely work-related and the learners were all working professionals rather than students. However, similar to workplace learning on the job, participation in a MOOC requires high levels of self-regulation and personal initiative, therefore a MOOC is an appropriate and a sufficiently comparable work-related context to examine SRL strategies. Milligan and Littlejohn (2016) analysed these healthcare professionals' narrative accounts of their learning strategies identifying evidence for a range of goal settings behaviours, focusing on both learning and performance goals, as well as for short-term and long-term orientation among these workers. Milligan et al (2016) also uncovered evidence of considerable self-efficacy among these health professionals.

What is known about how crowdworkers self-regulate their learning? There is paucity of research in this area: to date, only one published study examined self-regulatory learning strategies of crowdworkers (Margaryan, 2016; Margaryan, forthcoming). The findings suggest that crowdworkers undertake a wide range of self-regulatory learning strategies. In particular, the following strategies have been shown to be prevalent among crowdworkers: setting personal performance standards, setting short-term learning goals; monitoring and modifying learning strategies and the underpinning learning goals when needed; articulating explicit plans for achieving their learning goals; almost universal self-efficacy and intrinsic value of tasks; note taking and writing reflective notes on their learning progress; reaching out to others for feedback and to share their learning; observing and replicating other people's strategies, and explicitly reflecting on the long-term implications of what they learn through their crowdwork tasks for their career development (Margaryan, forthcoming). These findings are in line with those of Barnes et al. (2015) and Martin et al. (2014) who found indications of similar attributes of self-regulatory orientation including proactivity, self-motivation, initiative, self-efficacy and self-awareness among crowdworkers. Similar attributes and attitudes have been uncovered among entrepreneurs - a class of workers who may be comparable to crowdworkers (Polities, 2005; Ray and Wang, 2015; Shaver and Davies, 2017; Wang and Chugh, 2013). Overall, the emergent findings on crowdworkers' learning practices - albeit sparse - suggest that both types of crowdworkers are highly-self regulated and learning-oriented. In crowdwork, initiating and funding learning activities is the workers' responsibility and many crowdworkers appear to invest the time as well as their own financial resources in improving their skills (Margaryan, forthcoming). This contrasts with the findings from conventional employment settings were workers tend not to make such investment 
(Kim et al, 2004). Analysing similarities and differences in the patterns of use of SRL strategies between crowdworkers and conventional knowledge workers is an important step in understanding workplace learning processes, both within the emergent practice of crowdwork and within the more established organisational forms.

\section{METHODOLOGY}

Method and instrument: The method of this study is questionnaire survey. Data were collected using an online version of a published, validated instrument, Self-regulated Learning at Work Questionnaire, SRLWQ (Fontana, Milligan, Littlejohn and Margaryan, 2015). The SRLWQ is comprised of several scales/sections, including a mixture of Likert-scale items, multiple choice and open-ended questions, as detailed in Fontana et al (2015). In this paper, we focus on the findings of the SRL Strategies scale only.

The SRL Strategies scale included items derived from Zimmerman's three-phase model of selfregulated learning: planning including goal setting, strategic planning, self-efficacy and intrinsic value of task; implementation including task strategies and techniques and self-reflection/selfevaluation (Zimmerman, 2005). These measures are further detailed in Fontana et al. (2015). The items in this subscale were measured on a 5-point Likert scale (1-not at all true for me; 2-sometimes true for me; 3-quite true for me; 4-true for me, 5-very true for me).

Procedures and samples: An online version of the SRLWQ instrument was developed using Surveymonkey. Within the crowdwork sample, the survey was posted as a paid job task on Upwork and FigureEight, as well as distributed within several public and private groups for crowdworkers on social media such as Facebook and Reddit. Within the conventional knowledge work samples, the survey link was distributed via email to members of the Chartered Institute of Securities and Investment, an international professional body in the financial services sector and to the participants of two massive open online courses, on education (Change 11 MOOC) and healthcare (Fundamental of Clinical Trials MOOC). The details of the procedures and samples for each of the datasets are explained in detail in the following publications:

1. Crowdworkers $(\mathrm{n}=113)$, including microworkers and online freelancers (Margaryan, 2016)

2. Financial services professionals $(n=170)$ (Milligan, Fontana, Littlejohn, and Margaryan, 2015)

3. Educationalists who were participants of a massive open online course (MOOC) on Instructional Technology (the Change 11 MOOC, http://change.mooc.ca/about.htm ) $(\mathrm{n}=35)$ (Milligan, Littlejohn, and Margaryan, 2013)

4. Healthcare professionals who were participants of a MOOC 'Fundamentals of Clinical Trials' offered by Harvard University, https://www.edx.org/course/fundamentals-clinicaltrials-harvardx-hsph-hms214x $(\mathrm{n}=350)$ (Milligan and Littlejohn, 2014; 2016) 
Data analysis: For the analysis, the survey data were dichotomised, creating two sub-groups for each of the 4 main groups: (i) 'Yes', i.e. those who used any of the given SRL strategies at least some times merging the Likert-scale responses 2 (sometimes true for me), 3 (quite true for me), 4 (true for me) and 5 (very true for me); and (ii) 'No', i.e. those who never used the particular SRL strategies (1-not at all true for me). The non-parametric Chi-square test of independence was used to compare the groups regarding the use of each self-regulated learning strategy. This test is independent of the data distribution, which makes it robust to comparisons between groups with unequal sample sizes (McHugh, 2013). All the test assumptions were observed. One chi-square test was conducted per SRL item. The significance level of 0.05 was used.

\section{RESULTS AND DISCUSSION}

The findings on the similarities and differences in the patterns of use of SRL strategies between crowdworkers and conventional knowledge workers and between different types of crowdworkers are summarised in Table 1. Results for some items are not available (marked as "-" in Table 1). This is because the SRL scales were somewhat adapted for each specific context (the total sample numbers for each SRL item are reported with chi-square results). Statistically significant differences are highlighted in bold.

Table 1

Comparison of SRL strategies used by crowdworkers and conventional knowledge workers

\begin{tabular}{|c|c|c|c|c|c|}
\hline SRL strategies & $\begin{array}{l}\text { Crowd- } \\
\text { work } \\
(\% \text { Yes })\end{array}$ & $\begin{array}{l}\text { Finance } \\
(\% \text { Yes })\end{array}$ & $\begin{array}{l}\text { Educa- } \\
\text { tion } \\
(\% \\
\text { Yes }) \\
\end{array}$ & $\begin{array}{l}\text { Health } \\
(\% \\
\text { Yes })\end{array}$ & Chi-squares \\
\hline $\begin{array}{l}\text { 1. I set personal standards } \\
\text { for performance in my job }\end{array}$ & 98.2 & 99.4 & 100.0 & 96.3 & $\begin{array}{l}X^{2}(3, \mathrm{~N}=652)= \\
0.99, p>.05\end{array}$ \\
\hline $\begin{array}{l}\text { 2. I set short-term } \\
\text { learning goals }\end{array}$ & 96.5 & - & 91.4 & 94.6 & $\begin{array}{l}X^{2}(2, \mathrm{~N}=498)= \\
0.96, p>.05\end{array}$ \\
\hline $\begin{array}{l}\text { 3. I set long-term learning } \\
\text { goals }\end{array}$ & 93.8 & 99.4 & 80.0 & - & $\begin{array}{l}X^{2}(2, \mathrm{~N}=318)= \\
0.55, p>.05\end{array}$ \\
\hline $\begin{array}{l}\text { 4. I modify my strategies } \\
\text { when I don't make } \\
\text { progress while learning }\end{array}$ & 96.5 & 90.6 & - & 98.0 & $\begin{array}{l}X^{2}(2, \mathrm{~N}=633)= \\
0.72, p>.05\end{array}$ \\
\hline $\begin{array}{l}\text { 5. I adapt my learning } \\
\text { strategies to each specific } \\
\text { task or problem I am } \\
\text { working on }\end{array}$ & 100.0 & 98.8 & 94.3 & - & $\begin{array}{l}X^{2}(2, \mathrm{~N}=318)= \\
0.96, p>.05\end{array}$ \\
\hline
\end{tabular}




\begin{tabular}{|c|c|c|c|c|c|}
\hline $\begin{array}{l}\text { 6. I write down a plan of } \\
\text { how I'll achieve my } \\
\text { learning goals }\end{array}$ & 68.1 & 99.4 & - & - & $\begin{array}{l}X^{2}(1, \mathrm{~N}=283)= \\
0.005, p<.05\end{array}$ \\
\hline $\begin{array}{l}\text { 7. I am able to handle } \\
\text { most of the demands in } \\
\text { my job/course (self- } \\
\text { efficacy) }\end{array}$ & 99.1 & 100.0 & 91.4 & 99.1 & $\begin{array}{l}X^{2}(3, \mathrm{~N}=668)= \\
0.97, p>.05\end{array}$ \\
\hline $\begin{array}{l}8 \text {. I will be able to use } \\
\text { what I learned in my } \\
\text { work/course in the future }\end{array}$ & 96.5 & 96.5 & 94.3 & 99.4 & $\begin{array}{l}X^{2}(3, \mathrm{~N}=668)= \\
0.98, p>.05\end{array}$ \\
\hline $\begin{array}{l}\text { 9. It's important for me to } \\
\text { learn new things in this } \\
\text { job/course }\end{array}$ & 99.1 & 100.0 & 97.1 & 99.7 & $\begin{array}{l}X^{2}(3, \mathrm{~N}=668)= \\
0.97, p>.05\end{array}$ \\
\hline $\begin{array}{l}\text { 10. I prefer tasks that } \\
\text { arouse my curiosity, even } \\
\text { if I need to learn a lot to } \\
\text { achieve them }\end{array}$ & 98.2 & 100.0 & - & 99.4 & $\begin{array}{l}X^{2}(2, \mathrm{~N}=633)= \\
0.99, p>.05\end{array}$ \\
\hline $\begin{array}{l}\text { 11. I make notes/diagrams } \\
\text { to help organise my } \\
\text { thoughts when learning }\end{array}$ & 72.6 & 93.5 & 85.7 & 80.6 & $\begin{array}{l}X^{2}(3, \mathrm{~N}=668)= \\
0.26, p>.05\end{array}$ \\
\hline $\begin{array}{l}\text { 12. I collect information } \\
\text { from many different } \\
\text { sources when learning }\end{array}$ & 94.7 & 92.9 & 97.1 & 96.3 & $\begin{array}{l}X^{2}(3, \mathrm{~N}=668)= \\
0.98, p>.05\end{array}$ \\
\hline $\begin{array}{l}\text { 13. I treat the information } \\
\text { resources that I find as a } \\
\text { starting point and develop } \\
\text { my own ideas from them }\end{array}$ & 92.9 & 100.0 & - & 94.6 & $\begin{array}{l}X^{2}(2, \mathrm{~N}=633)= \\
0.79, p>.05\end{array}$ \\
\hline $\begin{array}{l}\text { 14. I ask myself how what } \\
\text { I am learning is related to } \\
\text { what I already know }\end{array}$ & 92.9 & 95.9 & 100.0 & 99.1 & $\begin{array}{l}X^{2}(3, \mathrm{~N}=668)= \\
0.94, p>.05\end{array}$ \\
\hline $\begin{array}{l}\text { 15. I apply lessons } \\
\text { learned from my previous } \\
\text { experience to my task } \\
\text { where appropriate }\end{array}$ & 98.2 & 100.0 & 100.0 & 98.6 & $\begin{array}{l}X^{2}(3, \mathrm{~N}=668)=1.0, \\
p>.05\end{array}$ \\
\hline $\begin{array}{l}\text { 16. When I have difficulty } \\
\text { to learn/do the task I ask } \\
\text { others for help }\end{array}$ & 84.1 & 90.0 & 77.1 & 82.9 & $\begin{array}{l}X^{2}(3, \mathrm{~N}=668)= \\
0.81, p>.05\end{array}$ \\
\hline $\begin{array}{l}\text { 17. I consider how what I } \\
\text { have learned may be of } \\
\text { interest to my colleagues } \\
\text { and others in my field }\end{array}$ & 81.4 & 100.0 & - & 90.0 & $\begin{array}{l}X^{2}(2, \mathrm{~N}=633)= \\
0.26, p>.05\end{array}$ \\
\hline
\end{tabular}




\begin{tabular}{lccccc}
\hline $\begin{array}{l}\text { 18. I think about what I } \\
\text { have learned after I finish }\end{array}$ & 95.6 & 96.5 & 94.3 & 98.0 & $\begin{array}{l}X^{2}(3, \mathrm{~N}=668)= \\
0.99, p>.05\end{array}$ \\
\hline $\begin{array}{l}\text { 19. I ask myself if there } \\
\text { were better ways to do the } \\
\text { tasks after I finish them }\end{array}$ & 92.0 & 97.6 & - & 94.9 & $\begin{array}{l}X^{2}(2, \mathrm{~N}=633)= \\
0.89, p>.05\end{array}$ \\
\hline $\begin{array}{l}\text { 20. I think about what I } \\
\text { have learned fits into the } \\
\text { 'bigger picture' of my } \\
\text { professional development }\end{array}$ & 92.0 & - & - & 98.9 & $\begin{array}{l}X^{2}(1, \mathrm{~N}=463)= \\
0.52, p>.05\end{array}$ \\
\hline
\end{tabular}

The chi-square tests uncovered a statistically significant difference in the use of only one SRL strategy - writing down a plan of how to achieve one's learning goals. Specifically, in our samples, crowdworkers were significantly less likely than the conventional knowledge workers to report using this strategy. Thus, whilst over $90 \%$ of crowdworkers do set personal performance goals and plan short- and long-term learning goals, fewer of them (68\%) appear to formalise these into a written plan. A possible explanation of this finding is that conventional knowledge workers are often required to articulate formal learning plans as part of annual performance review processes now routinely used in many organisations (Littlejohn et al, 2016; Margaryan et al, 2013) whilst crowdworkers are not required to do so. However, this result could be spurious, because at $p<.05$, $1 / 20$ tests could be expected to be falsely significant.

There are some seemingly considerable differences in the proportions of people reporting the use of some other SRL strategies (for example items 11 or 17 in Table 1), however none of these other differences were found to be statistically significant. These findings contradict previous research by Milligan et al (2015) and Littlejohn et al (2016) that suggested that the organisational context and the resources available to workers were key factors affecting workers' willingness to undertake SRL strategies in the workplace. Our findings suggest that other factors - either individual and/or other socio-cultural and environmental factors - could be more central in explaining the use of SRL strategies (Frese, Kring, Soose and Zempel, 1996). Individual differences in cognitive and physical abilities, personality traits and age may be contributing factors (Feldman and Ng, 2008). For example, age and career-stage have been shown to correlate with the willingness to engage in workplace learning and development, with early-career individuals having longer time horizons to make new learning easier to absorb and more likely to pay off (Kanfer and Ackerman, 2004). The nature of work tasks may be another key factor. Research in organisational psychology has shown that work tasks characterised by high work demands (responsibility) and high control over how the tasks are executed (discretion) lead to increased learning, self-efficacy, mastery, and motivation (Karasek and Theorell, 1990). Similarly, job empowerment, that is the extent to which a worker feels responsible for the outcomes of their work, has been suggested to increase motivation to engage in learning at their own initiative (London, 1993). Finally, previous research suggests that the extent of technological intensity and technological change within a job is positively correlated with motivation to engage in learning and development (Feldman et al, 2008). Technologically- 
intense environments, such as crowdwork platforms, may force people to learn continuously in order to stay current

Our results suggest that, despite operating outside conventional organisational structures and learning support scaffolds, crowdworkers are similar to conventional knowledge workers in terms of the learning strategies they use to self-regulate their learning in the workplace. Crowdworkers are just as likely as conventional knowledge workers to use a wide range of individually- and socially-oriented self-regulatory strategies including setting, monitoring and adapting their learning goals and strategies; considering the relevance of their learning to their peers and reaching out to others for help; and they are equally self-efficacious, self-reflective and motivated by learning opportunities within their work tasks as the conventional knowledge workers are. We cannot tell from the survey alone what exactly constitutes the individual and social dimension of crowdworkers' learning - for example, what specific types of learning goals and strategies they use and how they use these; or who the peers and professional networks they reach out to are (do these include other crowdworkers and, if so, how do they find and connect to others on the distributed and largely anonymous crowdwork platforms?). Follow-on interviews and fieldwork are required to understand crowdworkers' motivations and rationales underpinning their use of SRL strategies.

\section{CONCLUSIONS AND FUTURE RESEARCH}

This study explored differences in crowdworkers' and conventional knowledge workers' use of SRL strategies in the workplace. Workers' SRL strategies were scoped using an extant instrument, the Self-regulated Learning at Work Questionnaire, SRLWQ (Fontana et al, 2015). A total of 668 respondents from a range of crowdwork platforms (Upwork and FigureEight) and conventional knowledge work settings in the financial services, education and healthcare sectors filled out the questionnaire regarding the frequency of use of 20 key SRL strategies derived from Zimmerman's 3-phase model of self-regulation (Zimmerman, 2005). Findings suggest that the patterns of use of SRL strategies were similar across the crowdwork and conventional knowledge work settings. The only statistically-significant difference identified was in the SRL strategy 'Writing down a plan of how to achieve my learning goals'. Specifically, crowdworkers were significantly less likely than the conventional knowledge workers to use this strategy. We do not know from the survey what may have caused this difference. One explanation is that, as we know from previous workplace learning research, conventional knowledge workers in organisations are often required to articulate formal learning plans as part of organisational annual performance review processes, but crowdworkers are not required to do so. Therefore, even though crowdworkers do set short- and long-term learning goals and strategies, they may not be willing to invest the time in articulating their learning plans in writing, perhaps because they may not see an added value in doing so. Overall, the study suggests that, despite operating outside conventional organisational structures with their explicit and tacit learning support mechanisms and opportunities, crowdworkers nevertheless are similar to conventional knowledge workers in terms of the learning strategies they use to self-regulate their learning in the workplace. 
We suggest several different directions for future research. First, follow-on studies are required to understand the factors - individual or environmental - that stimulate people to engage in workplace learning using SRL strategies outside formal organisational settings. Specifically, further interviews and fieldwork are required to understand crowdworkers' motivations and rationales underpinning their use of SRL strategies and workplace learning activities. Second, these survey findings should be validated and refined using a larger sample of crowdworkers and more and larger samples of conventional knowledge workers from other domains. The only significant difference uncovered in this study was based on comparison of two samples only (crowdwork and finance, $n=283$ ), and this needs to be expanded and further refined with a larger sample. Third, it is important to understand the reasons why workers use the particular SRL strategies and how they use them. For example, it is useful to scope the conditions that trigger each particular self-regulatory learning strategy, both in crowdwork and in conventional workplace settings, and for each SRL strategy, to analyse workers' motivations to undertake the strategy. Interviews and fieldwork (for example, observations and think-aloud protocols) could help illustrate and contextualise the learning processes underpinning these behavioural strategies.

\section{ACKNOWLEDGEMENTS}

This research was funded by Alexander von Humboldt Foundation (Germany) and hosted within the department of Work Sociology at Goethe University Frankfurt. I would like to thank Professor Heather Hofmeister and her entire team for hosting me in their wonderfully peaceful, stimulating, collegiate and scholarly environment. I would like to thank Dr Caroline di Bernardi Luft (Queen Mary University of London) for advice on the data analysis. 


\section{REFERENCES}

Barnes, S.-A., Green, A., \& de Hoyos, M. (2015). Crowdsourcing and work: Individual factors and circumstances influencing employability. New Technology, Work and Employment, 30(1), 16-31.

Billett, S. (2010) (Ed.). Learning through practice: Models, traditions, orientations and approaches. Dordrecht: Springer.

Billett, S., Harteis, Ch., \& Etelapelto, A. (2008) (Eds.). Emerging perspectives of workplace learning. Rotterdam: Sense Publishers.

Boekaerts, M., Pintrich, P., \& Zeidner, M. (2005), (Eds). Handbook of self-regulation. San Diego: Academic Press.

Bolhuis, S., \& Voeten, M. (2004). Teachers' conceptions of student learning and own learning. Teachers and Teaching: Theory and Practice, 10, 77-98.

Boshuizen, E., Bromme, R., \& Gruber, H. (2004), (Eds.). Professional learning: Gaps and transitions on the way from novice to expert. Dordrecht: Kluwer.

Corporaal, G.F., \& Lehdonvirta, V. (2017). Platform sourcing: How Fortune 500 firms are adopting online freelancing platforms. Oxford Internet Institute: Oxford. Retrieved 17 November 2017 from https://www.oii.ox.ac.uk/publications/platform-sourcing.pdf

Degryse, Ch. (2016). Digitalisation of the economy and its impact on labour markets. Working paper 2016.02, European Trade Union Institute. Retrieved 17 November 2017, from https://www.etui.org/Publications2/WorkingPapers/Digitalisation-of-the-economy-and-its-impact-on-labour-markets

Dochy, P., Gijbels, D., Segers, M., \& van den Bossche, P. (2011), (Eds.). Theories of learning for the workplace: Building blocks for training and professional development programs. London: Routledge.

Earley, P. C., \& Kanfer, R. (1985). The influence of component participation and role models on goal acceptance, goal satisfaction and performance. Organizational Behavior and Human Decision Processes, 36, 378-98.

van Eekelen, I., Boshuizen, H. and Vermunt, J. (2005). Self-regulation in higher education teacher learning. Higher Education, 50, 447-71.

Eraut, M. (1994). Developing professional knowledge and competence. London: Routledge.

Eurofound (2015). New forms of employment. Publications Office of the European Union: Luxembourg. Retrieved 17 November 2017, from https://www.eurofound.europa.eu/publications/report/2015/working-conditions-labourmarket/new-forms-of-employment

Felstead, A., Fuller, A., Jewson, N., \& Unwin, L. (2009). Improving working as learning. London: Routledge.

Fontana, P., Milligan, C., Littlejohn, A., \& Margaryan, A. (2015). Measuring self-regulated learning in the workplace: An instrument validation. International Journal of Training and Development, 19(1), 32-52.

Frese, M., Kring, W., Soose, A., \& Zempel, J. (1996). Personal initiative at work: Differences between East and West Germany. Academy of Management Journal, 39, 37-63. Retrieved 17 November 2017, from http://www.jstor.org/stable/256630

Gadiraju, U., Kawase, R., \& Dietze, S. (2014). A taxonomy of microtasks on the web. In Proceedings of HT 2014 Conference (pp. 218-223), September 1-4, 2014, Santiago, Chile.

Green, A., de Hoyos, M., Barnes, S.-A., Baldau, B., \& Behle, H. (2014). Exploratory research on Internet-enabled work exchanges and employability. EC Institute for Prospective Technological Studies.

Gupta, N. (2017). An ethnographic study of crowdwork via Amazon Mechanical Turk in India. PhD thesis, University of Nottingham. Retrieved 17 November 2017, from http://eprints.nottingham.ac.uk/41062/

Huws, U. (2014). Labor in the Global Digital Economy. New York: Monthly Review Press. 
Huws, U., Spencer, N., \& Joyce, S. (2016). Crowd work in Europe. University of Hertfordshire, UK. Retrieved 08 October 2018, from http://researchprofiles.herts.ac.uk/portal/files/10749125/crowd_work in_europe_draft_report_last_version.pdf

Illeris, K. (2011). The fundamentals of workplace learning. London: Routledge.

Irani, L. (2015). The cultural work of microwork. New Media and Society, 17(5), 720-739.

Kanfer, R., Chen, G., \& Pritchard, R. (2008) (Eds). Work motivation: Past, present and future. New York/London: Routledge.

Kanfer, R., \& Ackerman, P. (2004). Aging, adult development, and work motivation. Academy of Management Review, 29, 440-458. Retrieved 17 November 2017, from http://www.jstor.org/stable/20159053

Karasek, R., \& Theorell, T. (1990). Healthy work: Stress, productivity, and the reconstruction of working life. New York: Basic Books.

Kim, K., Collins Hagedorn, M., Williamson, J., \& Chapman, C. (2004). Participation in adult education and lifelong learning: 2000-01 (NCES 2004-050). U.S. Department of Education, National Center for Education Statistics. Washington, DC: U.S. Government Printing Office. Retrieved 17 November 2017, from https://nces.ed.gov/pubs2004/2004050.pdf

Kuek, Siou Chew, et al. (2015). The global opportunity in online outsourcing. Washington, DC: World Bank. Retrieved 17 November 2017, from http://documents.worldbank.org/curated/en/138371468000900555/The-globalopportunity-in-online-outsourcing

Lehdonvirta, V. (2017, 10 July). The online gig economy grew 26\% over the past year. Retrieved 17 November 2017 , from https://www.oii.ox.ac.uk/blog/the-online-gig-economy-grew-26-over-the-past-year/

Lehdonvirta, V., \& Ernkvist, M. (2011). Converting the virtual economy into development potential. Washington, DC: infoDev/World Bank. Retrieved 17 November 2017, from http://www.infodev.org/infodevfiles/resource/InfodevDocuments_1056.pdf

Littlejohn, A., \& Milligan, C., Fontana, P., \& Margaryan, A. (2016). Professional learning through everyday work: How finance professionals self-regulate their learning. Vocations and Learning, 9(2), 207-226.

Littlejohn. A, \& Margaryan, A. (2014) (Eds). Technology-enhanced professional learning: Processes, practices and tools. London: Routledge.

Locke, E., \& Latham, G. (2013). New developments in goal setting and task performance. New York/London: Routledge.

Lord, R. G., Diefendorff, J. M., Schmidt, A. M., \& Hall, R. J. (2010). Self-regulation at work. Annual Review of Psychology, 61, 543-68.

Malloch, M., Cairns, L., Evans, K., \& O’Connor, B. (2011), (Eds.). The SAGE handbook of workplace learning. London: SAGE.

Manyika, J., Lund, S., Robinson, K., Valentino, J., and Dobbs, R. (2015). A labour market that works: Connecting talent with opportunity in the digital age. McKinsey Global Institute. Retrieved 17 November 2017, from http://www.mckinsey.com/global-themes/employment-and-growth/connecting-talent-with-opportunity-in-thedigital-age

Margaryan, A. (forthcoming). Workplace learning in crowdwork platforms. New Technology, Work and Employment.

Margaryan, A. (2016). Understanding crowdworkers' learning practices. In Proceedings of Internet, Policy and Politics 2016 Conference, Oxford Internet Institute, University of Oxford. Retrieved 17 November 2017, from http://ipp.oii.ox.ac.uk/sites/ipp/files/documents/FullPaper-CrowdworkerLearning-MargaryanForIPP$100816 \% 281 \% 29 . \mathrm{pdf}$

Margaryan, A., Littlejohn, A., \& Milligan, C. (2013). Self-regulated learning in the workplace: Learning goal attainment strategies and factors. International Journal of Training and Development, 17(4), 245-259. 
Martin, D., O’Neill, J., Gupta, N., Hanrahan, B. (2016). Turking in a global labour market. Computer-Supported Cooperative Work, 25(1), 39-77.

McHugh, M. (2013). The chi-square test of independence. Biochemia Medica, 23(2), 143-149.

Milligan, C., \& Littlejohn, A. (2016). How health professionals regulate their learning in massive open online courses. The Internet and Higher Education, 31, 113-121.

Milligan, C., Fontana, R.P., Littlejohn, A., and Margaryan, A. (2015). Self-regulated learning behaviour in the finance industry. Journal of Workplace Learning, 27(5), 387-402.

Nickerson, J. (2014). Crowd work and collective learning. In Littlejohn, A., \& Margaryan, A. (Eds.), Technologyenhanced Professional Learning (pp. 39-49). London: Routledge.

Pew Research Centre (2016). Gig work, online selling and home sharing. Retrieved 17 November 2017, from http://www.pewinternet.org/2016/11/17/gig-work-online-selling-and-home-sharing/

Polities, D. (2005). The process of entrepreneurial learning: A conceptual framework. Entrepreneurship Theory and Practice, 29(4), 399-424.

Ray, D., \& Wang, C. (2015). Entrepreneurial learning: New perspective in research, education and practice. London: Routledge.

Schmidt, F. (2017). Digital labour markets in the platform economy: Mapping the political challenges of crowd work and gig work. Friedrich-Ebert Foundation, Germany. Retrieved 17 November 2017, from http://library.fes.de/pdffiles/wiso/13164.pdf

Shaver, K., \& Davies, A. (2017). The psychology of entrepreneurship: A selective review and a path forward. In Ahmetoglu, G., Chamorro-Premuzic, Th., Klinger, B., \& Karcisky, T. (Eds.), The Wiley handbook of entrepreneurship (pp. 95-118), Chichester: Wiley \& Sons.

Silberman, S., Irani, L., \& Ross. J. (2010). Ethics and tactics of professional crowdwork. Crossroads, 17(2), 39-43.

Sitzmann, T., \& Ely, K. (2011). A meta-analysis of self-regulated learning in work-related training and educational attainment: What we know and where we need to go. Psychological Bulletin, 137(3), 421-42.

Tillema, H., \& Kremer-Hayon, L. (2002). Practice what we preach: teacher educators' dilemmas in promoting selfregulated learning. Teaching and Teacher Education, 18, 593-607.

Wang, C., \& Chugh, H. (2013). Entrepreneurial learning: Past research and future challenges. International Journal of Management Reviews, 16(1), 24-61. 